\title{
International experts met in Germany to discuss recent trends in anion exchange membranes
}

\author{
by Dr. Wiebke Germer (NEXT ENERGY)
}

Ion exchange membranes are used in various applications like fuel cells, electrolyzers, or batteries. During the last years, alkaline anion exchange membranes attracted more and more attention. Very promising is their application in fuel cells due to the fact that less cost intensive non-noble metal catalysts can be employed in alkaline environment. Therefore, alkaline membranes and their applications were the main topic of the "Workshop on Ion Exchange Membrane Applications", which was held in Bad Zwischenahn (Germany) on June $17^{\text {th }}-18^{\text {th }} 2014$.

19 talks were given by membrane specialists from academic research facilities and professionals from producing industry. Besides the scientific agenda, the social program and excursion to the NEXT ENERGY laboratories were well used for establishing and cultivating contacts between researchers and industrial representatives.

The workshop was organized by the NEXT ENERGY - EWE Research Centre for Energy Technology (Germany) in collaboration with the Korea Institute of Science and Technology - KIST (South Korea) and the Jagiellonian University of Krakow (Poland). "Due to the success of the first two events we already started to plan the follow up event for 2015. We like to establish a sequel of annual events that will keep the focus on anion exchange membranes to promote their application," stated Dr. Dirk Henkensmeier (KIST, South Korea), co-organizer of the event.

The next "Workshop on lon Exxchange Membranes for Energy Applications" (EMEA2015) will take place in Bad Zwischenahn, Germany, on June $22^{\text {nd }}-24^{\text {th }} 2015$. Detailed information will be published on www.next-energy.de/EMEA2015.html in the near future. In order to give an impression of the program of the past workshop, this feature article presents four excerpts of the scientific talks by courtesy of the respectively named authors.

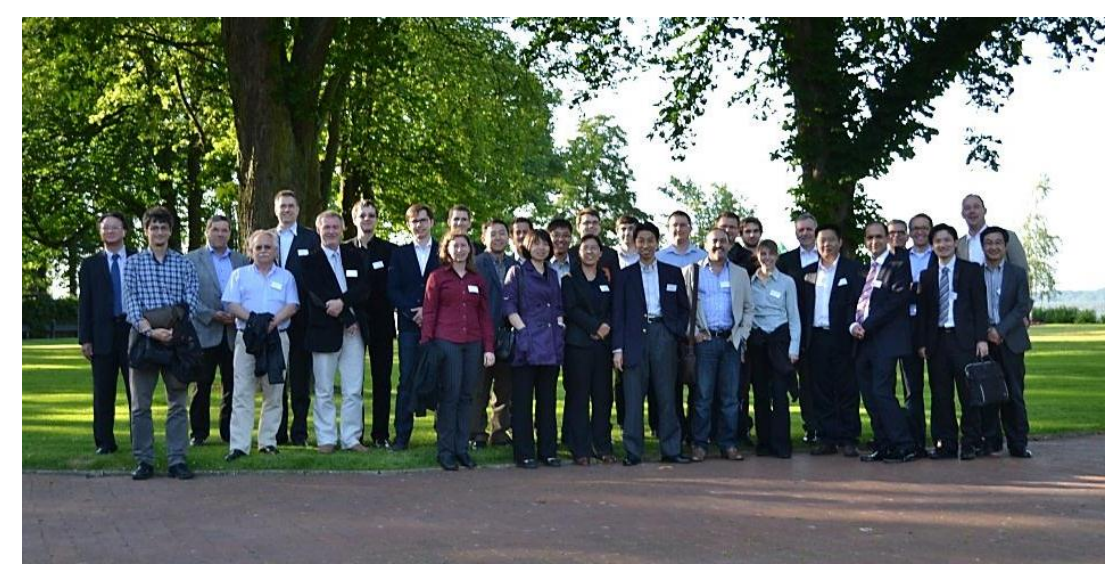

Figure 1. Experts on ion exchange membranes met for the second time in Bad Zwischenahn (Germany) to exchange views during the international workshop. 


\title{
Present challenges in Alkaline Membrane Fuel Cell technology
}

\author{
Dario R. Dekel (CellEra Inc. $)^{A}$
}

One of the major challenges humanity faces nowadays is to supply an alternative, affordable and clean source of energy. In order to meet this challenge, intensive research and development of highly efficient electrochemical devices are needed. In recent decades, fuel cell technology has been undergoing revolutionary developments. A fundamental progress in this technology has been the replacement of electrolyte solutions with polymer electrolytes, which makes fuel cell devices more compact in size and higher in power density. Currently, proton exchange membrane fuel cell (PEMFC) based on acidic (proton exchange) polymer electrolytes, typically Nafion ${ }^{\circledR}$, are widely employed. While PEM-FC technology is already mature, its application is still very limited due to high-cost and fuel versatility issues.

The disruptive new Anion Exchange Membrane Fuel Cell (AEM-FC) technology, also called Alkaline Membrane Fuel Cell (AMFC) technology, promises to solve the main cost barriers of the PEM-FC as in principle it allows using non-precious metal catalysts as well as low cost hydrocarbon based membranes. AEM-FCs have been rapidly developing for the past five years, and latest improvements done in this technology on the whole are more than impressive. For the first time, breakthroughs in anion exchange membranes (AEMs) and non-precious electrocatalysts for oxidation reduction reaction (ORR) have recently taken place. However, while first AEMs with minimum conductivity required for practical fuel cell applications have been recently developed, the stability of the functional groups of the membrane in real AEM-FCs requires now major improvements in order to be applicable.

To recognize AEM-FC as a real promising technology, there are yet several development challenges that we must address prior to its general acceptance and future large-scale introduction. These development challenges include anion conductive polymers (membrane and ionomers) with improved stability mainly at temperatures higher than $60^{\circ} \mathrm{C}$. Advances in these fields will assure rapid entrance to existing market opportunities. At CellEra we have developed a unique functionalization process to the main polymer that allows us to increase the operation temperature of the AEM-FC without drying the cells. This in turn allows stabilizing the cell voltage during long period of operation. Using this novel functionalization process, CellEra's $2 \mathrm{~kW}$ AEM-FC stack was successfully operated during several months at relatively high temperatures and cell voltages. Figure 2 shows CellEra's state-of-the-art AEM-FC 2kW stack performance.

CellEra's AEM-FC stack was operated in cycling mode (ON/OFF cycles), simulating real operation of a telecom back up power unit. The figure shows the gross output power (blue circles) and average cell voltage (red circles) of each cycle during a few months of operation. As can be seen, the average cell voltage of the AEM-FC stack was kept above $0.5 \mathrm{~V}_{\text {avg }}$ per cell and stable during all the operated months. This result represents the state-of-the-art in AEM-FC technology. 


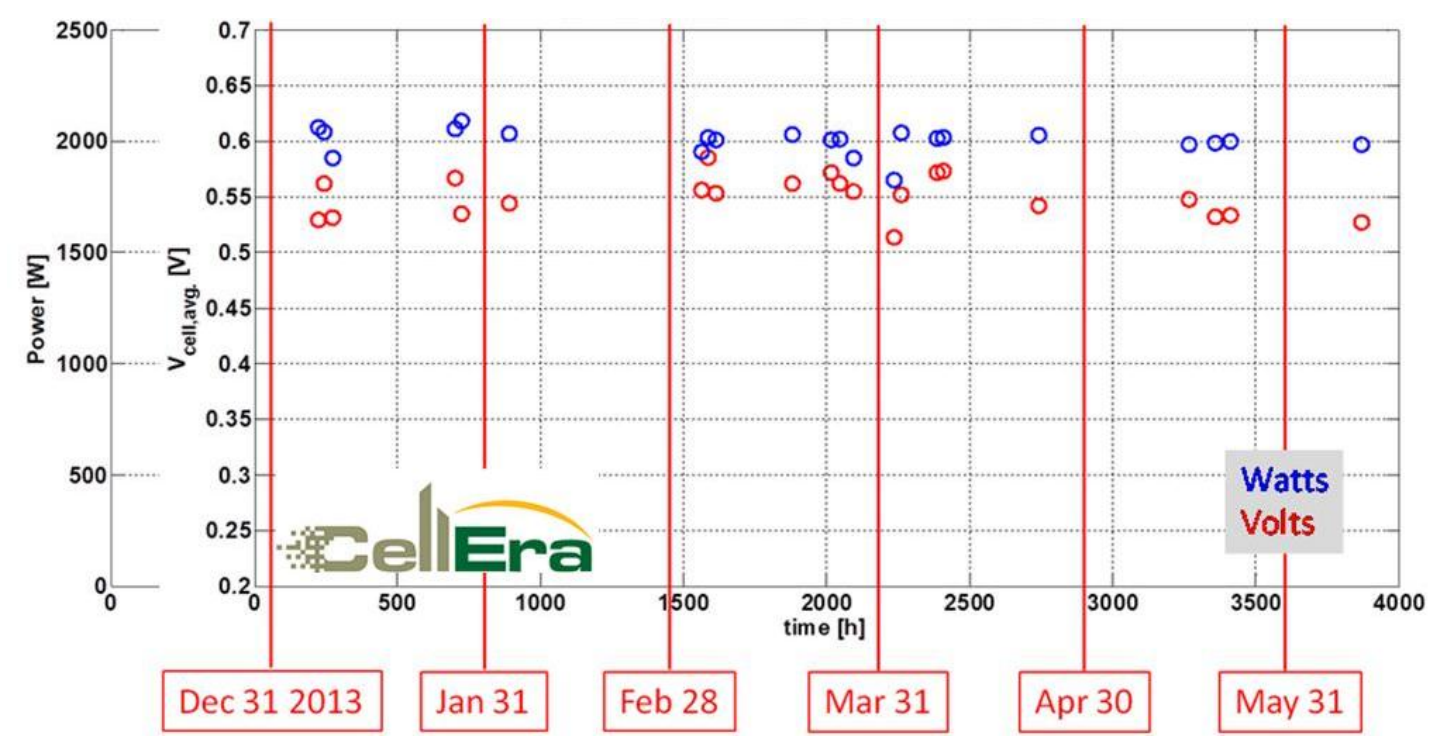

Figure 2. CellEra's state-of-the-art AEM-FC stack operated in cycling mode (ON/OFF cycles), demonstrating stable average cell voltage values during all the operated months. Gross output power (blue circles) and average cell voltage (red circles) of each cycle during a few months of operation.

\section{Novel AEM-Base-Acid Blends for the Potential Application in Electromembrane-Processes}

Jochen Kerres (University of Stuttgart) ${ }^{B}$

The group of J. Kerres deals since many years with the application of acid-base blend concepts to proton-exchange ionomer membranes both for low- $\mathrm{T}$ fuel cell applications $\left(\mathrm{T}<100^{\circ} \mathrm{C}\right)$ and intermediate-T fuel cell applications. The acid-base concept for low-T fuel cell applications comprises mixing of a sulfonated ionomer with a polymeric base where the polymeric base acts as macromolecular ionical cross-linker within the membrane matrix, leading to membranes where the water uptake and cation conductivity can be controlled by the ionical cross-linking density ${ }^{[1]}$ At intermediate-T fuel cell membranes, the polymeric base (in most cases a chemically stable polymer from the class of polybenzimidazoles (PBI)) is mixed with a minor amount of a sulfonated or phosphonated polymer where the sulfonated polymer acts as acidic macromolecular ionical crosslinker for the basic polymer, which improves the mechanical and chemical stability of the membrane markedly, compared to the pure basic polymer. ${ }^{[2]}$ In the last step the base-excess blend membrane is doped with phosphoric acid which acts as the proton-conductor in the membrane in an intermediate-T fuel cell $\left(\mathrm{T}=100-220^{\circ} \mathrm{C}\right)$. In this contribution the acid-base concept is extended to anion-exchange membranes (AEM). The preparation of the novel acid-base AEMs is depicted schematically in Figure 3.

The characterization of the chemical stability of the novel membranes in $1 \mathrm{~N} \mathrm{KOH}$ at $90^{\circ} \mathrm{C}$ for 5 days revealed that the membranes were much more stable than the commercial AEM A201 from Tokuyama. Whereas A201 membranes exhibited only $13 \%$ of their original $\mathrm{Cl}^{-}$conductivity after 5 days of degradation, the novel blend membranes achieved up to $82 \%$ of their starting value. Moreover, membranes were manufactured that achieved $\mathrm{Cl}^{-}$conductivities of up to $38.4 \mathrm{mS} / \mathrm{cm}$ at $70{ }^{\circ} \mathrm{C}$, thus exceeding the performance of the commercial A201 membrane. 


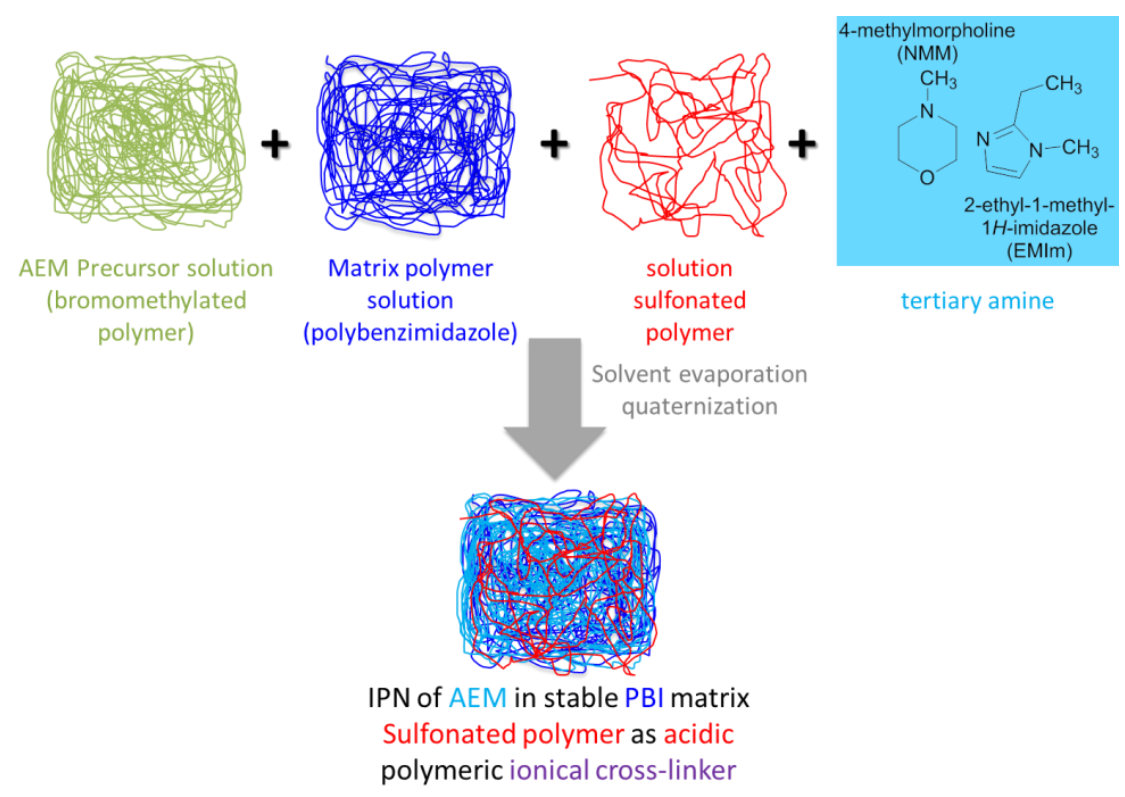

Figure 3: Acid-base concept for AEMs.

\section{Radiation-grafted anion-exchange ionomers for alkaline polymer electrolyte fuel cell electrodes}

John Varcoe and Simon Poynton (University of Surrey) ${ }^{c}$

Alkaline anion-exchange polymer electrodes are being developed for use as the membranes (alkaline anion-exchange membranes: AAEM) and as anion exchange ionomers (AEI: used as anion conducting catalyst binder) in membrane electrode assemblies (MEAs) for electrochemical devices such as alkaline polymer electrolyte fuel cells (APEFC). ${ }^{[3]}$ Such polymer electrolytes conduct anion such as hydroxide ions but are insulation towards electrons. The most common class of AAEM and AEIs involve quaternary ammonium as the positively charged polymer bound groups, although there are numerous studies worldwide on developing cationic head-groups that are more stable to the presence of hydroxide (without loss of conductivity); however, trimethylammonium-type headgroups are still reasonably stable in alkali when kept fully hydrated as the hydroxide anions are less nucleophilic when surrounded by a full hydration sphere. Many different types of polymer backbones have been investigated for use in AAEMs and AEIs including polysulfones and other polyaromatics. ${ }^{[4]}$ Contrary to historical perceptions, these AAEMs and AEIs can have conductivities (when fully hydrated) approaching those of Nafion $\left(>100 \mathrm{mS} \mathrm{cm}^{-1}\right)$ at temperatures $>60^{\circ} \mathrm{C}$.

Another class of AAEM involves the radiation-grafting of vinyl monomers onto preformed partially fluorinated, as poly(ethylene-co-tetrafluoroethylene), ETFE, polymer films. ${ }^{[5]}$ A typical process involves the electron-beam irradiation of ETFE films in air, followed by reaction with vinylbenzyl chloride and a subsequent quaternisation process involving amines such as trimethylamine (to yield the target benzyltrimethylammonium head-groups). These radiation-grafted (RG)-AAEMs can have conductivities $>80 \mathrm{mS} \mathrm{cm}^{-1}$ at $80^{\circ} \mathrm{C}$ and have been tested in hydrogen-oxygen APEFCs with peak power densities of $>500 \mathrm{~mW} \mathrm{~cm}^{-2}$ at temperatures of around $60^{\circ} \mathrm{C}$. The use of RG-AAEMs facilitate the fundamental evaluation of different chemistries, such as the relative comparison of AAEMs with the same backbone and head-group chemistries and other properties: e.g. AAEMs with different thicknesses and the same ion-exchange capacities (IEC) and chemistry, the same thicknesses and 
chemistry but different IECs, or the same thicknesses and IECs but with different head-group chemistries.

However, ETFE-based materials are insoluble to common solvents, especially those that are useful for processing catalyst-ionomer inks. As such, there has been much less research on the development of AEls using the RG approach. To investigate if such AEls are viable, ETFE powders (rather than films) of various grades have been radiation-grafted. ${ }^{[6]}$ Incorporation of such RG-AEI powders does allow the fabrication of MEAs with reasonable performances (see Figure 4 - SION1 is a first generation AEI). The next step is the identification of the combination of ETFE-grade and solvent to allow for the development of a fully solubilised RG-AEI to produce the next generation of RG-MEAs and electrodes for use in various all-solid-state alkaline electrochemical devices.

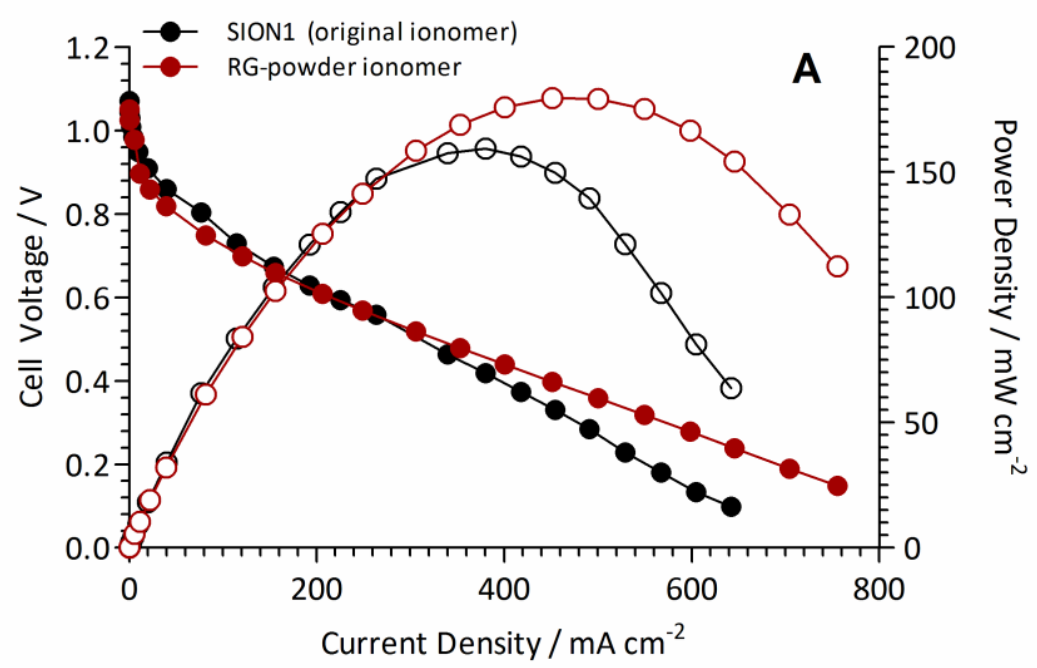

Figure 4. Comparison of SION1 (a first generation AEI) and a radiation-grafted powder ionomer.

\section{Anion exchange membrane fuel cell vehicles using hydrazine hydrate as a fuel}

\section{Tomokazu Sakamoto (Daihatsu Motors) ${ }^{D}$}

In the near future, so that for the general public to be able to purchase a fuel cell vehicle (FCV) at a proper price and to use without inconvenience: 1. Costs of FCV need to be reduced by designing compact FC systems and using inexpensive materials. 2. The infrastructure which stores, supplies, and transports fuel safely should be required.

In recent years, anion exchange membrane fuel cells (AEMFCs) using hydrazine hydrate as a fuel attracted attention as a procedure to address above issues of FCVs. Hydrazine hydrate is a relatively stable fuel and is not flammable at concentrations below $60 \%$. The overall reaction of direct hydrazine hydrate fuel cells (DHFCs) is described by the following equation.

$\mathrm{N}_{2} \mathrm{H}_{4}+4 \mathrm{OH}^{-} \rightarrow \mathrm{N}_{2}+4 \mathrm{H}_{2} \mathrm{O}+4 \mathrm{e}^{-}$

The theoretical potential of this reaction is $1.61 \mathrm{~V}$, which is high in comparison to hydrogen fueled polymer electrolyte membrane fuel cells. Furthermore, as a liquid fuel, hydrazine hydrate does not require special handling procedures for storage, supply, and transportation, in contrast to hydrogen. 
Hydrazine hydrate has been historically used as fuel for fuel cells from the 1960s. Dr. Karl Kordesch manufactured an alkaline fuel cell electric motorcycle in 1967. It is said that fuel consumption of hydrazine hydrate reached $80 \mathrm{~km} \mathrm{~L}^{-1}$. In Japan, the National Institute of Advanced Industrial Science and Technology (AIST), Panasonic, and Daihatsu together manufactured a pickup truck type fuel-cell vehicle in 1972. The car was the first fuel-cell vehicle in Japan and ran a maximum speed of $100 \mathrm{~km} \mathrm{~h}$ ${ }^{1}$ (60 mph), powered by the alkali type fuel cell using $\mathrm{KOH}$ electrolyte generating $5.2 \mathrm{~kW}$. However, it had a problem of the durability that $\mathrm{CO}_{2}$ in the air reacts with $\mathrm{KOH}$.

By using anion exchange membrane, since there are no potassium ions, the durability problem of the alkaline fuel cell can be solved. The anion exchange membrane enables realization of a brand-new alkaline direct hydrazine fuel cell. It is desired to develop highly efficient and durable anion-exchange membrane. Moreover, inexpensive materials such as $\mathrm{Fe}, \mathrm{Co}$, and $\mathrm{Ni}$ can be applied as electrocatalyst due to the alkaline environment inside of anion exchange membrane fuel cells.

Since Jasinski et al. firstly reported about non-PGM catalysts for oxygen reduction reaction in 1964, several other non-PGM catalysts such as oxide catalyst and complex catalyst for non-PGM ORR have been suggested until now. In our development, complex catalyst in which Fe atom is coordinated by $\mathrm{N}$ and/or $\mathrm{C}$ atoms was used as cathode. Metal complexes such as Fe aminoantipyrine or Fe phenanthroline were used as a precursor, and it has catalytic activity for ORR after impregnation, washing (etching by acid solution), drying, and annealing. The weight ratio of Fe for total catalyst weight is a mere $1 \mathrm{wt} . \%$. However, the catalytic activity of the Fe complex catalyst for ORR in alkaline electrolyte matches that of Pt catalysts.

As hydrazine oxidation anode catalyst, $\mathrm{Ni}$-based metal catalysts have attracted attention and we have confirmed that Ni-based binary and/or ternary catalysts have high catalytic activity by using a combinatorial rapid survey. Especially NiZn catalysts showed enhanced activity due to their alloy effect. Using NiZn as an anode catalyst in DHFCs a high power density of $500 \mathrm{~mW} \mathrm{~cm}^{-2}$ was observed.

Figure 5 shows a DHFCV in which the fuel cell system is installed under the floor. The DHFCV was developed as collaborative research with University, research institute, and industry. Status of research, development of FCV, and cell performance of DHFCs indicate that DHFC is a technology to promote hydrogen energy. However, we are required to build upon the technology of materials, stack design, and FC system to make FCV accessible to the customer.

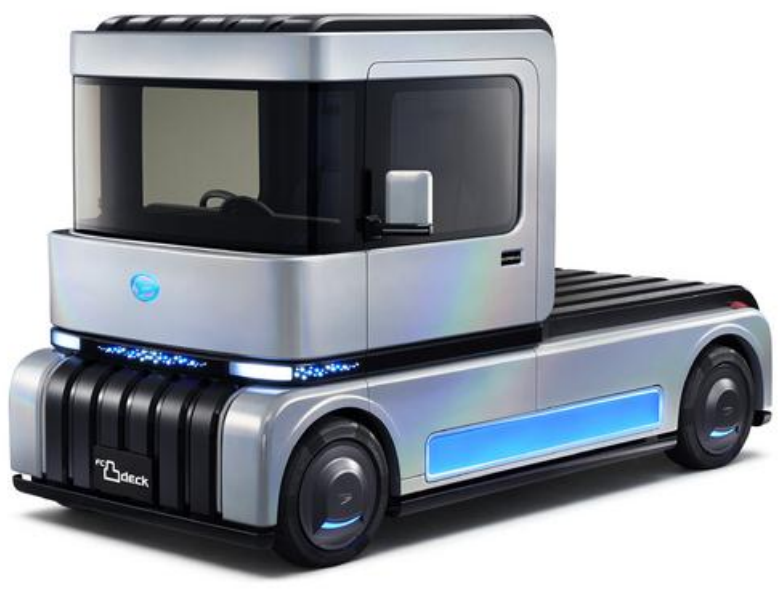

Figure 5. Direct hydrazine hydrate fuel cell vehicle (DHFCV) by Daihatsu. 


\section{Workshop on lon Exchange Membranes}

for Energy Applications

EMEA2015

\section{2-24 June 2015}

\section{Bad Zwischenahn, Germany}

www.next-energy.de/EMEA2015.html

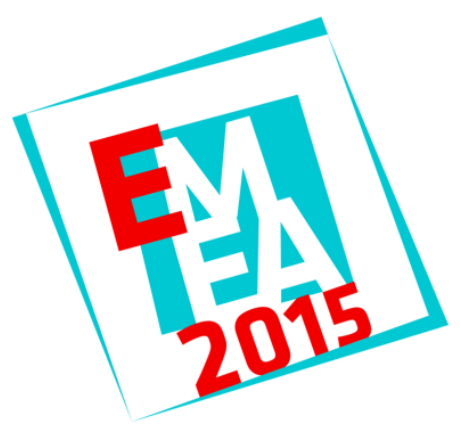

\section{EMEA@next-energy.de}

\section{Acknowledgment}

This work was supported by funding received from the KORANET Joint Call on Green Technologies (www.koranet.eu).

NEXT ENEGY would like to thank the authors for kindly providing the scientific short reports:

A Dario Dekel: CellEra Inc., Caesarea Business and Industrial Park, Caesarea, Israel.

${ }^{B}$ Jochen Kerres: University of Stuttgart, Institute of Chemical Process Engineering, Boeblinger Str. 78, D-70199 Stuttgart, Germany.

c John Varcoe: University of Surrey, Department of Chemistry, Guildford GU2 7XH, UK.

${ }^{D}$ Tomokazu Sakamoto: R\&D Division, Daihatsu Motor Co., Ltd., 3000 Yamanoue, Ryuo, Gamo, Shiga 520-2593, Japan. / Japan Science and Technology Agency, CREST, 4-1-8 Honcho, Kawaguchi, Saitama 332-0012, Japan.

\section{References}

${ }^{[1]}$ J. Kerres, A. Ullrich, Th. Häring, M. Baldauf, U. Gebhardt, W. Preidel: Preparation, Characterization, and Fuel Cell Application of New Acid-Base Blend Membranes, J. New Mat. Electrochem. Syst. (2000) $3229-239$.

${ }^{[2]}$ Q.F. Li, H.C. Rudbeck, A. Chromik, J. O. Jensen, C. Pan, T. Steenberg, M. Calverley, N. J. Bjerrum, J. Kerres: Properties, Degradation and High Temperature Fuel Cell Test of Different Types of PBI and PBI Blend Membranes, J. Memb. Sci. (2010) 347(1-2) 260- 270.

${ }^{[3]}$ J. R. Varcoe, P. Atanassov, D. R. Dekel, A. M. Herring, M. A. Hickner, P. A. Kohl, A. R. Kucernak, W. E. Mustain, K. Nijmeijer, K. Scott, T. Xu, L. Zhuang: Anion-exchange membranes in electrochemical energy systems, Energy Environ. Sci. (2014), in-press. http//dx.doi.org/10.1039/C4EE01303D

${ }^{[4]}$ J. Pan, C. Chen, Y. Li, L. Wang, L. Tan, G. Li, X.Tang, L. Xiao, J. Lu, L. Zhuang: Constructing ionic highway in alkaline polymer electrolytes, Energy Environ. Sci. (2014) 7(1) 354-360.

http//dx.doi.org/10.1039/c3ee43275k

${ }^{[5]}$ O. I. Deavin, S. Murphy, A. L. Ong, S. D. Poynton, R. Zeng, H. Herman, J. R. Varcoe: Anion-exchange membranes for alkaline polymer electrolyte fuel cells: Comparison of pendent

benzyltrimethylammonium- and benzylmethylimidazolium- head-groups, Energy Environ. Sci. (2012) 5(9) 8584-8597. http//dx.doi.org/10.1039/C2EE22466F

${ }^{[6]}$ S. D. Poynton, R. C. T. Slade, T. Omasta, W. E. Mustain, R. Escudero Cid, P. Ocón, J. R. Varcoe: Preparation of radiation-grafted powders for use as anion exchange ionomers in alkaline polymer electrolyte fuel cells, J. Mater. Chem. A (2014) 2(14) 5124-5130.

http//dx.doi.org/10.1039/C4TA00558A

For more information, contact: Dr Wiebke Germer, Division Fuel Cells, NEXT ENERGY - EWE Research Centre for Energy Technology

Carl-von-Ossietzky-Strasse 15, D-26129 Oldenburg, Germany. Tel: +49 44199906319 , 
Email: wiebke.germer@next-energy.de,

Web: www.next-energy.de 